\title{
Regulation and clinical significance of the hypoxia-induced expression of ANGPTL4 in gastric cancer
}

\author{
HIROSHI KUBO ${ }^{1}$, YOSHIHIKO KITAJIMA ${ }^{1,2}$, KEITA KAI $^{3}$, JUN NAKAMURA ${ }^{1}$, SHUUSUKE MIYAKE ${ }^{1}$, \\ KAZUYOSHI YANAGIHARA ${ }^{4}$, KIYOTO MORITO $^{1}$, TOMOKAZU TANAKA ${ }^{1}$, \\ MASAAKI SHIDA $^{1}$ and HIROKAZU NOSHIRO ${ }^{1}$ \\ ${ }^{1}$ Department of Surgery, Saga University Faculty of Medicine, Saga 849-8501; ${ }^{2}$ Department of Surgery, \\ National Hospital Organization Higashisaga Hospital, Saga 849-0101; ${ }^{3}$ Department of Pathology and Biodefense, \\ Saga University Faculty of Medicine, Saga 849-8501; ${ }^{4}$ Division of Translational Research, \\ Exploratory Oncology Research and Clinical Trial Center, National Cancer Center, Kashiwa, Chiba 277-8577, Japan
}

Received September 14, 2014; Accepted June 8, 2015

DOI: $10.3892 / \mathrm{ol} .2015 .4011$

\begin{abstract}
Solid tumors are often exposed to hypoxia. Hypoxia inducible factor (HIF)-1 $\alpha$ upregulates numerous target genes associated with the malignant behavior of hypoxic cancer cells. A member of the angiopoietin family, angiopoietin-like protein 4 (ANGPTL4) is a hypoxia-inducible gene. The present study aimed to clarify whether ANGPTL4 is regulated by HIF- $1 \alpha$ in gastric cancer cells. The study also assessed whether ANGPTL4 expression is associated with clinicopathological factors or HIF-1 $\alpha$ expression in gastric cancer tissues. Hypoxia-induced ANGPTL4 expression was quantitatively analyzed using reverse transcription-quantitative polymerase chain reaction (RT-qPCR) in 10 gastric cancer cell lines. RT-qPCR was further employed to investigate the HIF-1 $\alpha$ dependency of ANGPTL4 expression using HIF-1 $\alpha$-knockdown transfectant 58As9-KD and control 58As9-SC gastric cancer cells. The HIF-1 $\alpha$ and ANGPTL4 expression levels were immunohistochemically analyzed in 170 gastric cancer tissue specimens and were assessed for any correlations with the clinicopathological factors and/or patient survival. Subsequently, hypoxia-induced ANGPTL4 expression was observed in 7 out of 10 gastric cancer cell lines. The hypoxic induction of ANGPTL4 was almost preserved in the 58As9-KD cells compared with that observed in the 58As9-SC cells, while the induction of known HIF-1 $\alpha$ target gene, carbonic anhydrase 9, was completely suppressed in the 58As9-KD cells. In the gastric cancer tissues, ANGPTL4 expression was inversely correlated with the tumor depth, whereas HIF-1 $\alpha$ expression was positively correlated with venous invasion. A survival analysis revealed that the expression of ANGPTL4 was significantly correlated with a longer
\end{abstract}

Correspondence to: Dr Yoshihiko Kitajima, Department of Surgery, Saga University Faculty of Medicine, 5-1-1 Nabeshima, Saga 849-8501, Japan

E-mail: kitajiy@hosp.go.jp

Key words: ANGPTL4, HIF-1, gastric cancer, hypoxia survival time, whereas that of HIF-1 $\alpha$ was correlated with a shorter survival time. In conclusion, the present findings indicate that hypoxia-induced ANGPTL4 expression is independent of HIF-1 $\alpha$ in hypoxic gastric cancer cells. ANGPTL4 may be a favorable marker for predicting a long survival time, whereas HIF- $1 \alpha$ predicts a poor prognosis, in gastric cancer patients. The hypoxic environment independently induces ANGPTL4 and HIF-1 $\alpha$, which are believed to exhibit adverse effects on tumor progression.

\section{Introduction}

Gastric cancer is the fourth most common malignancy and the second leading cause of cancer-related mortality worldwide $(1,2)$. Patients with advanced gastric cancer frequently have metastases to the lymph nodes and occasionally to distant organs. Lymph node metastasis is controlled to a certain extent in these patients by curative procedures, although gastric cancer patients with distant organ metastasis exhibit a poor prognosis. Stage classification, composed of the tumor depth, lymph node metastasis and distant metastasis, generally predicts the post-operative prognosis of the patient. However, the survival time differs among patients with the same stage, as the biological characteristics of individual tumors vary. Therefore, identifying novel biological molecules determining the tumor aggressiveness of gastric cancer may be useful for precisely predicting patient survival. Moreover, clarifying further biological markers for gastric cancer would improve individual pathogenetic treatment matching for patients with gastric cancer.

A hypoxic environment is frequently present in solid tumors and has been recognized to be associated with high-grade cancers and anticancer drug resistance (3). Hypoxia inducible factor-1 (HIF-1) is a transcription factor that plays a central role in the hypoxic environment by controlling the expression of target genes that regulate energy metabolism, cell proliferation, cell death, cell migration and angiogenesis (4-10). HIF-1 is a heterodimer composed of a constitutively expressed HIF-1 $\beta$ subunit and an $\mathrm{O}_{2}$ level-regulated HIF-1 $\alpha$ subunit (3-7). At present, HIF-1 $\alpha$ is widely known to be a master regulator 
that accelerates tumor invasion and metastasis in solid tumors, including gastric cancers (3-5). In our recent study, a gastric cancer cell line, 58As9-KD, was established in which HIF-1 $\alpha$ expression is completely knocked down by small interfering (si)RNA transfection, and this transfectant was used to describe the critical role of HIF-1 $\alpha$ expression in the development of the peritoneal metastasis of gastric cancer (11). HIF-1 $\alpha$ overexpression has been immunohistochemically detected in a variety of cancer types, including prostate, breast, lung, brain, gastric, and head and neck cancers $(3,4,5,10)$, and is associated with tumor aggressiveness, vascularity, treatment failure and mortality, resulting in a poor patient prognosis $(3,4,5,8,9,10,12)$.

Angiopoietin-like protein 4 (ANGPTL4) is a member of the angiopoietin family and is also known as peroxisome proliferator-activated receptor $\gamma$-induced angiopoietin-related protein, fasting-induced adipose factor or hepatic fibrinogen/angiopoietin-related protein. This protein is a circulating glycoprotein that is highly expressed within adipose tissue, the liver and the placenta (13-16). The native full-length ANGPTL4 (flANGPTL4) is a fusion protein consisting of an N-terminal coiled-coil domain (nANGPTL4) and a large $\mathrm{ANG}$ /fibrinogen-like $\mathrm{COOH}$-terminal domain (cANGPTL4) (17-19); these three domains have been shown to exhibit distinct biological functions (18). Furthermore, ANGPTL4 has been reported to exhibit diverse effects, including lipid metabolism, glucose metabolism, vascular permeability, angiogenesis, wound healing and tumorigenesis, in normal and malignant cells (17,20-23). Among these biological effects, recent studies have focused on the critical roles of ANGPTL4 in tumor progression in various cancers, including hepatocellular carcinoma (HCC) (24), colorectal cancer $(25-27)$, breast cancer $(28,29)$, prostate cancer $(30)$, renal cell carcinoma $(31,32)$ and Kaposi's sarcoma $(33,34)$. In addition, ANGPTL4 is known to be a hypoxia-induced gene. It was previously reported that HIF-1 $\alpha$ directly upregulates ANGPTL4 in HCC cells, and a high level of ANGPTL4 secretion in HCC patients is correlated with intrahepatic metastasis (24). However, there have been few studies on the association between gastric cancer and ANGPTL4 expression (35). Furthermore, the association between ANGPTL4 and the HIF-1 $\alpha$ expression has not yet been studied in gastric cancer.

The present study evaluated the hypoxia-induced expression of ANGPTL4 in various gastric cancer cell lines. Using 58As9-KD cells, the study assessed whether ANGPTL4 expression is dependent of HIF-1 $\alpha$ under hypoxic conditions $\left(\begin{array}{ll}1 \% & \mathrm{O}_{2}\end{array}\right)$. Immunohistochemical examinations were also performed using surgically excised specimens obtained from 170 patients with gastric cancer in order to determine the the association between ANGPTL4 and HIF-1 $\alpha$ expression and the clinicopathological factors.

\section{Materials and methods}

Cell lines and treatment. A total of 10 gastric cancer cell lines (MKN1, MKN7, MKN28, MKN45, MKN74, HSC45, HSC57, 44As3, 58As9 and KATO-III) were used for the following studies. HSC45, HSC57, 44As3 and 58As9 were provided by Dr K. Yanagihara (National Cancer Institute, Tokyo, Japan), while the remaining six cell lines were purchased from
Cell Bank, Riken BioResource Center (Ibaraki, Japan). The cells were cultured in RPMI-1640 medium (Sigma-Aldrich, St. Louis, MO, USA) and maintained under either normoxic $\left(20 \% \mathrm{O}_{2}\right.$ and $5 \% \mathrm{CO}_{2}$ in air) or hypoxic $\left(1 \% \mathrm{O}_{2}, 5 \% \mathrm{CO}_{2}\right.$ and $94 \% \mathrm{~N}_{2}$ ) conditions.

Patients. A total of 170 patients with advanced gastric cancer who consecutively underwent curative surgery at the Department of Surgery, Saga University Hospital (Saga, Japan) between June 2000 and December 2008 were enrolled in the present study. None of the patients presented with hepatic, peritoneal or distant metastasis or tumor cells in the peritoneal fluid. Stage classification was performed according to the guidelines of the Japanese Gastric Cancer Association (36). The clinicopathological characteristics of the patients were recorded (Table I).

Informed consent to use the tissue specimens was obtained from each patient, and the study protocol was approved by the Ethics Committee of Saga University Faculty of Medicine (no. 26-45).

Establishment of the HIF-1 $\alpha$-knockdown cell line, 58As9-KD, using siRNA. The pBAsi-hU6 Pur DNA plasmid vector (Takara Biotechnology, Shiga, Japan) was used to construct a HIF-1 $\alpha$ siRNA plasmid by inserting a siRNA-coding sequence under the U6 promoter. The sequences of siRNA targeting HIF-1 $\alpha$ and control scrambled siRNA were designed as follows: HIF-1 $\alpha$ (5'-CCACATTCACGTATATGAT-3') and scrambled (5'-TCTTAATCGCGTATAAGGC-3'). The 58As9 cells were transfected using a MicroPorator-mini (MP-100; Digital Bio Technology, Seoul, Korea) according to the manufacturer's instructions. In order to generate HIF-1 $\alpha$-knockdown cells (58As9-KD) and control cells (58As9-SC) with stable transfection of the aforementioned sequences, the cells were selected with puromycin (Sigma-Aldrich) at a concentration of $1.0-2.5 \mu \mathrm{g} / \mathrm{ml}$ and maintained in complete medium supplemented with puromycin, as previously described (11).

Western blot analysis. Whole cell lysates from cultured cells were prepared using lysis buffer, as described previously (11). Aliquots containing $30 \mu \mathrm{g}$ of protein were subjected to 4-12\% Bis-Tris gel electrophoresis (NuPAGE; Invitrogen) and transferred onto Amersham Hybond-ECL membranes (GE Healthcare, Buckinghamshire, UK) in transfer buffer. Subsequent to being blocked with $5 \%$ skimmed milk for $30 \mathrm{~min}$, the membranes were incubated with primary antibodies overnight at $4^{\circ} \mathrm{C}$. The primary antibodies were monoclonal rabbit anti-human HIF-1 $\alpha$ (cat. no. EP1215Y; 1:1,000 dilution; Epitomics, Burlingame, CA, USA) and anti- $\beta$-actin (cat. no. A5441; 1:10,000 dilution; Sigma-Aldrich). Following incubation with the corresponding goat anti-rabbit IgG secondary antibodies (cat. no. sc-2004; 1:10,000 dilution; Santa Cruz Biotechnology, Inc., Dallas, TX, USA), the signals were developed using the Amersham ECL Plus Western Blotting Detection System (GE Healthcare).

Total RNA extraction and reverse transcription-quantitative polymerase chain reaction $(R T-q P C R)$. Total RNA was extracted from each cell line using an extraction kit (ISOGEN; Nippon Gene, Osaka, Japan). For each cell line, $1 \mu \mathrm{g}$ RNA was 
Table I. Characteristics of the patients and tumors.

\begin{tabular}{|c|c|}
\hline Characteristics & Value \\
\hline Patients, n (\%) & $170(100.0$ \\
\hline \multicolumn{2}{|l|}{ Age, years } \\
\hline Median & 71 \\
\hline Range & $26-88$ \\
\hline \multicolumn{2}{|l|}{ Gender, n (\%) } \\
\hline Male & $113(66.5)$ \\
\hline Female & $57(33.5)$ \\
\hline \multicolumn{2}{|l|}{ Surgery, n (\%) } \\
\hline Distal gastrectomy & $71(41.8)$ \\
\hline Total gastrectomy & $98(57.6)$ \\
\hline Proximal gastrectomy & $1(0.59)$ \\
\hline \multicolumn{2}{|l|}{ Histology, n (\%) } \\
\hline Differentiated & $68(40.0)$ \\
\hline Undifferentiated & $102(60.0)$ \\
\hline \multicolumn{2}{|l|}{ Tumor depth, n (\%) } \\
\hline 2 & $46(27.0)$ \\
\hline 3 & $69(40.6)$ \\
\hline $4 \mathrm{a}$ & $51(30.0)$ \\
\hline $4 b$ & $4(2.4)$ \\
\hline \multicolumn{2}{|c|}{ Lymph node metastasis, $\mathrm{n}(\%)$} \\
\hline 0 & $63(37.1)$ \\
\hline 1 & $36(21.2)$ \\
\hline 2 & $26(15.3)$ \\
\hline $3 a$ & $16(9.4)$ \\
\hline $3 b$ & $29(17.0)$ \\
\hline
\end{tabular}

Lymphatic invasion, $\mathrm{n}(\%)$

$\begin{array}{lr}- & 36(21.2) \\ + & 134(78.8) \\ \text { Vascular invasion, n (\%) } & \\ - & 90(52.9) \\ + & 80(47.1) \\ \text { Stage, n (\%) } & \\ \text { IB } & 28(16.5) \\ \text { IIA } & 36(21.2) \\ \text { IIB } & 26(15.3) \\ \text { IIIA } & 29(17.0) \\ \text { IIIB } & 26(15.3) \\ \text { IIIC } & 25(14.7) \\ \text { Adjuvant } & \\ - & 102(60.0) \\ + & 68(40.0)\end{array}$

converted into complementary (c)DNA using a reverse transcription reaction kit (ReverTra Ace; Toyobo Co., Ltd., Osaka, Japan). The cDNA was used as a template for PCR, and RT-qPCR was performed using the Light Cycler instrument system (Roche Diagnostics GmbH, Mannheim, Germany), as previously described (11). The primers were designed according to the cDNA sequences (GenBank, Bethesda, MD) as follows: ANGPTL4 sense, 5'-TCCGTACCCTTCTCCACTTG-3' and antisense, 5'-AGTACTGGCCGTTGAGGTTG-3' (124 bp); carbonic anhydrase 9 (CA9) sense, 5'-CCGAGCGACGCAGCCTTTGA-3' and antisense, 5'-GGCTCCAGTCTCGGCTACCT-3' (252 bp); and $\beta$-actin sense, 5'-TCGTGCGTGACATTAAGGAG-3' and antisense, 5'-GTCAGGCAG CTCGTAGCTCT-3' (109 bp). After performing a denaturation step at $95^{\circ} \mathrm{C}$ for $3 \mathrm{~min}$, 50 cycles PCR amplification was conducted (15 sec of denaturation at $95^{\circ} \mathrm{C}, 5 \mathrm{sec}$ of annealing at $60^{\circ} \mathrm{C}$ and $10 \mathrm{sec}$ of extension at $72^{\circ} \mathrm{C}$ ). The quantitative values were normalized to the $\beta$-actin expression. All experiments were performed in triplicate, and the mean values calculated.

Immunohistochemistry. The immunohistochemical analyses of ANGPTL4 and HIF-1 $\alpha$ were performed as previously described (4,35). In brief, formalin-fixed, paraffin-embedded samples were sectioned to $4-\mu \mathrm{m}$ wide. For antigen retrieval, the tissue sections were heated in $1 \mathrm{mM}$ EDTA ( $\mathrm{pH} 8.0$ ) in a microwave for $5 \mathrm{~min}$. The slides were then incubated in the humidified chamber at room temperature for $2 \mathrm{~h}$ with a primary polyclonal goat anti-human ANGPTL4 antibody (cat. no. AF3485; 1:500 dilution; R\&D Systems, Inc., Minneapolis, MA, USA) or primary monoclonal mouse anti-human HIF-1 $\alpha$ antibody (cat. no. NB100-105; 1:200 dilution; Novus Biologicals, Littleton, CO, USA). Subsequent to being washed in phosphate-buffered saline, biotinylated anti-goat immunoglobulin $\mathrm{G}(\mathrm{IgG})$ for ANGPTL4 and anti-mouse IgG for HIF-1 $\alpha$, conjugated to a peroxidase-labeled dextran polymer (Dako EnVision, Carpinteria, CA, USA), were used as secondary antibodies. The 3,3'-diaminobenzidine substrate kit (Nichirei Co., Tokyo, Japan) was used for color development. Finally, nuclear counterstaining was performed with Mayer's hematoxylin solution. The cells in the fundic gland in the normal gastric tissue served as the internal positive control for ANGPTL4 immunostaining (35). The ANGPTL4 expression was divided into three categories according to the percentage of positively-stained tumor cells as follows: $0-10 \%$, negative; $11-30 \%$, weakly positive; and $>31 \%$, strongly positive. The HIF-1 $\alpha$ expression was divided into positive and negative categories, as previously described (4). The HIF-1 $\alpha$ expression was assessed in the center, as well as at the invasive front of the tumor in each section. Positive HIF-1 $\alpha$ expression was determined if nuclear staining was observed in the cancer center and at the invasive front.

Statistical analysis. The statistical analyses were performed using the computer software program IBM SPSS Statistics 19 for Windows (IBM SPSS, Armonk, NY, USA). Differences in the mean values were evaluated using Student's t-test. Analyses comparing the ANGPTL4 expression levels were performed with the $\chi^{2}$ test for independence. Univariate and multivariate analyses for disease-specific survival were performed using Cox's proportional hazards model. Survival curves were generated using the Kaplan-Meier method, and statistical differences were compared using the log-rank test. $\mathrm{P}<0.05$ was considered to indicate a statistically significant difference.

\section{Results}

ANGPTL4 expression in the gastric cancer cell lines. The ANGPTL4 mRNA expression levels in the 10 gastric cancer 
A

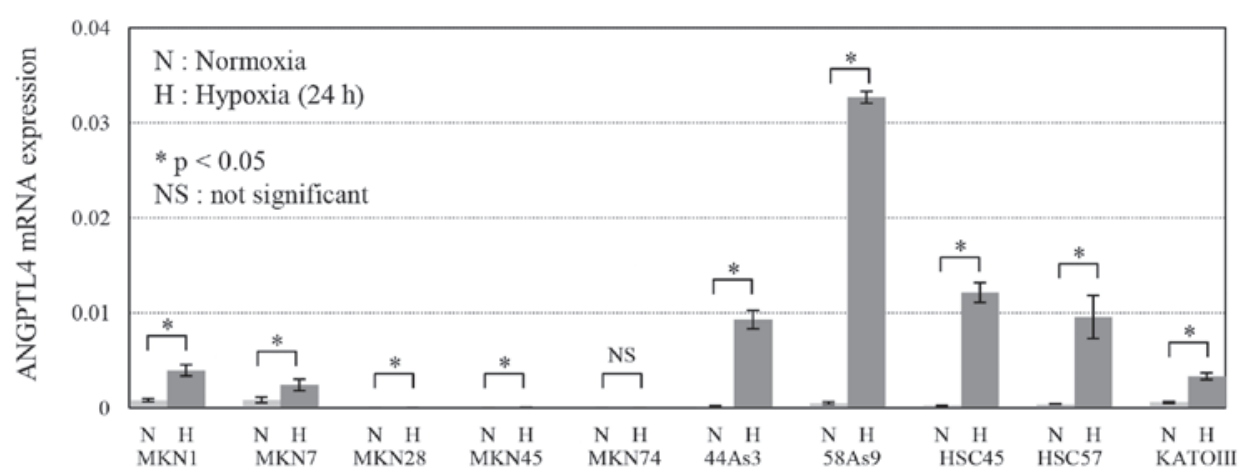

$\mathbf{B}$

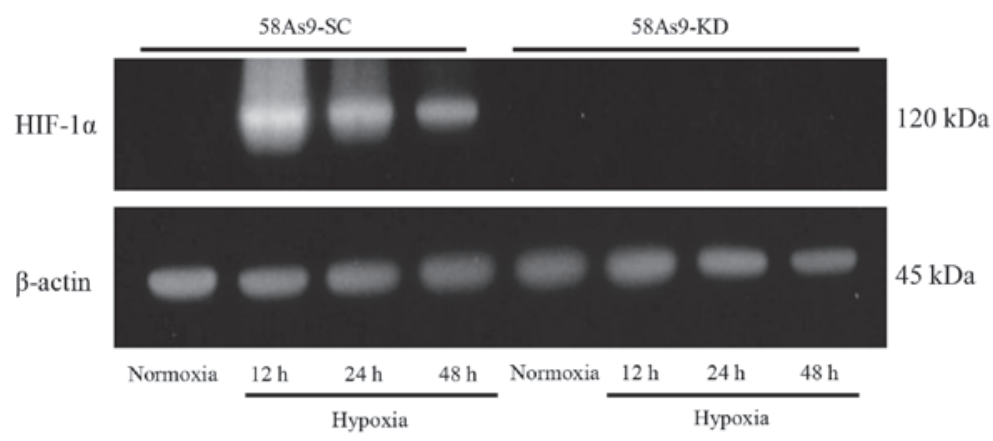

C
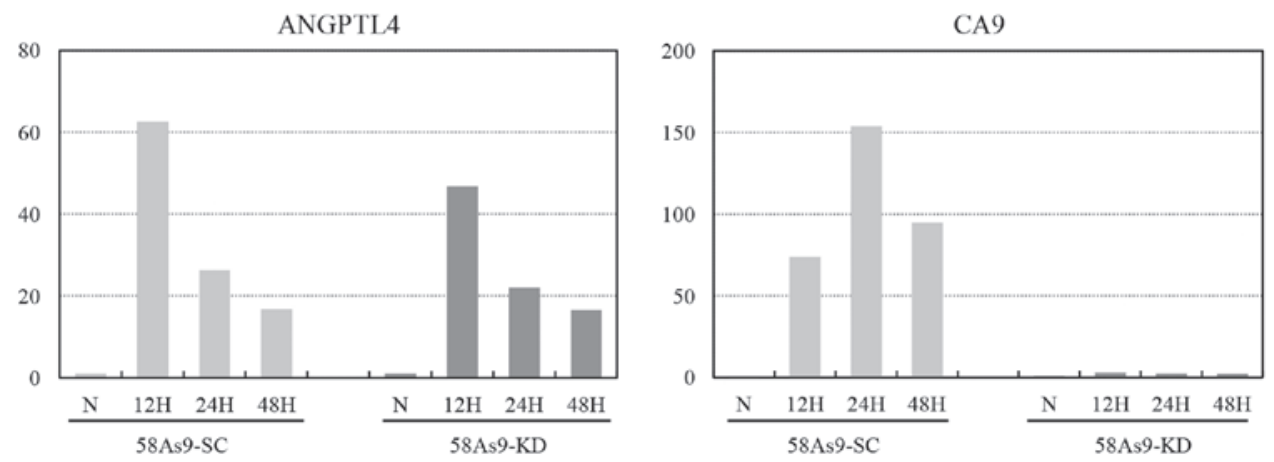

N: Normoxia, 12H: Hypoxia 12 h, 24H: Hypoxia 24 h, 48H: Hypoxia 48 h

Figure 1. ANGPTL4 expression in the gastric cancer cell lines and HIF-1 $\alpha$-knockdown cells. (A) RT-qPCR for ANGPTL4 was performed in 10 gastric cancer cell lines exposed to normoxia $\left(\mathrm{N} ; 20 \% \mathrm{O}_{2}\right)$ or hypoxia $\left(\mathrm{H} ; 1 \% \mathrm{O}_{2}\right)$ for $24 \mathrm{~h}$. ANGPTL4 mRNA expression was significantly induced under hypoxia in the MKN1, MKN7, 44As3, 58As9, HSC45, HSC57 and KATOIII cells, but not in the MKN28, MKN45 or MKN74 cells. "P<0.05; NS, not significant. (B) Western blot analysis of HIF-1 $\alpha$ expression in the HIF-1 $\alpha$-knockdown 58As9-KD cells and control 58As9-SC cells under normoxia and hypoxia. The HIF-1 $\alpha$ expression was strongly induced in the 58As9-SC cells under hypoxia for 12, 24 and $48 \mathrm{~h}$. By contrast, HIF-1 $\alpha$ expression was completely suppressed in the 58As9-KD cells under hypoxia for 12, 24 and $48 \mathrm{~h}$. (C) RT-qPCR analysis of the CA9 and ANGPTL4 expression in the 59As9-SC and 58As9-KD cells under normoxia $(\mathrm{N})$ and hypoxia $(\mathrm{H})$ for 12, 24 and $48 \mathrm{~h}$. The hypoxia-induced expression of CA9 mRNA was drastically suppressed in the 58As9-KD cells compared with that noted in the 58As9-SC cells. By contrast, mRNA expression was preserved under hypoxia (at 12, 24 and $48 \mathrm{~h}$ ) in the 58As9-KD cells compared with that observed in the 58AS9-SC cells. HIF-1 $\alpha$, hypoxia inducible factor $1 \alpha$; ANGPTL4, angiopoietin-like protein 4; CA9, carbonic anhydrase 9; RT-qPCR, reverse transcription-quantitative polymerase chain reaction.

cell lines under normoxic and hypoxic conditions are shown in Fig. 1A. Under normoxia, ANGPTL4 was expressed in 7 cell lines (MKN1, MKN7, 44As3, 58As9, HSC45, HSC57 and KATOIII), but not 3 other cell lines (MKN28, MKN45 and MKN74). Notably, the expression levels were significantly elevated under hypoxia in the 7 positive cell lines. Meanwhile, hypoxia did not induce any expression in the 3 negative cell lines.

In order to investigate the effects of HIF-1 $\alpha$-knockdown on gene expression, HIF-1 $\alpha$-knockdown 58As9-KD and control 58As9-SC cells were used. Fig. 1B shows the complete knockdown of HIF-1 $\alpha$ expression in the 58As9-KD cells under hypoxia for 12,24 and $48 \mathrm{~h}$, compared with the strong induction of HIF-1 $\alpha$ expression noted in the 58As9-SC cells. Between these two transfectants, the mRNA expression levels of the known HIF- $1 \alpha$ target gene, CA9, and ANGPTL4 were compared under conditions of normoxia and hypoxia (Fig. 1C). Consequently, the mRNA expression of CA9 in the 58As9-SC cells was significantly induced under hypoxia, where the fold induction was 74 times for $12 \mathrm{~h}, 154$ times for $24 \mathrm{~h}$ and 95 times for $48 \mathrm{~h}$. The hypoxic induction of CA9 mRNA was markedly decreased in the 58As9-KD cells, in which the fold induction was 1.3 times for $12 \mathrm{~h}, 2.4$ times for $24 \mathrm{~h}$ and 2.3 times for $48 \mathrm{~h}$. On the other hand, the ANGPTL4 

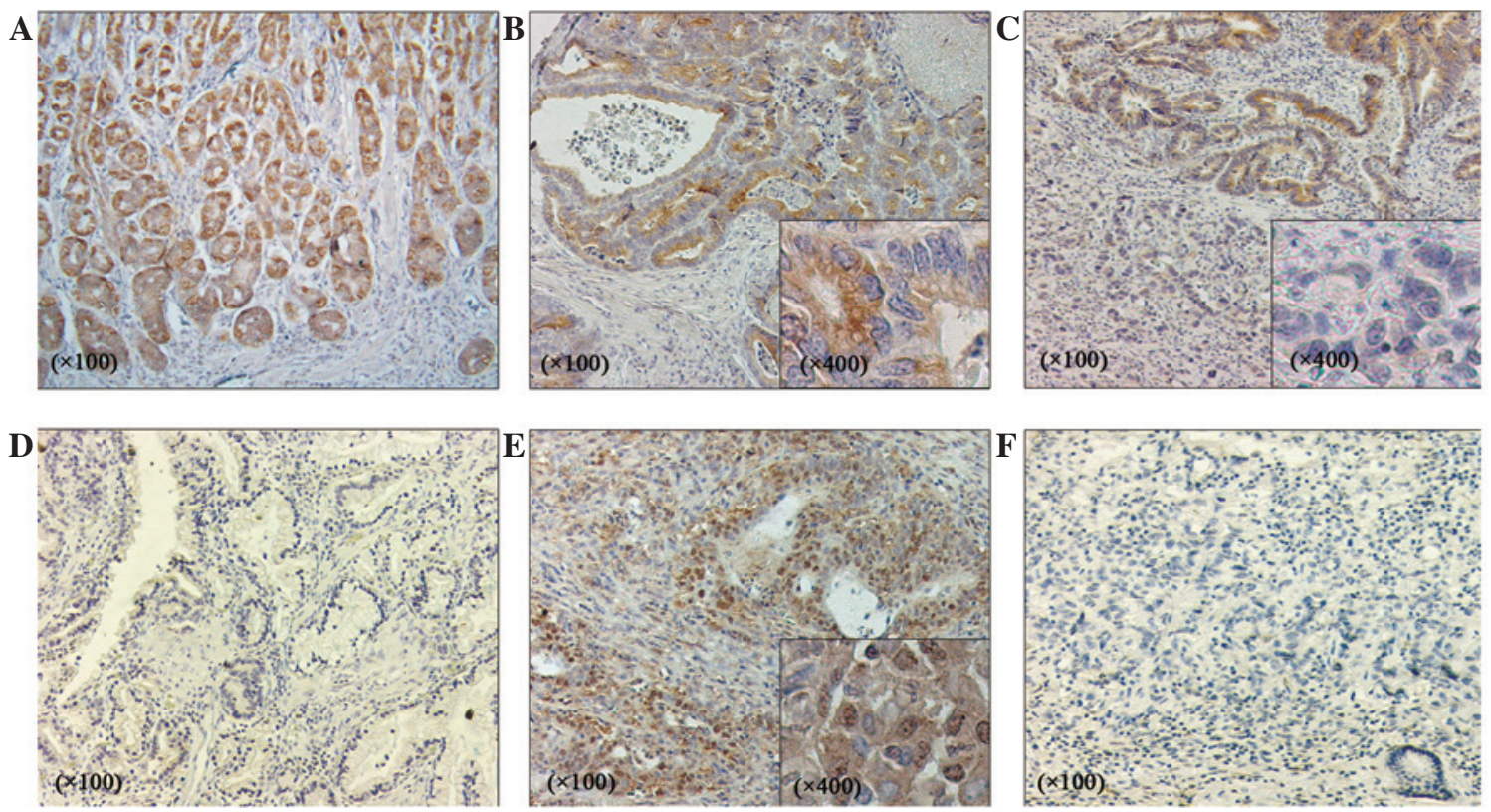

Figure 2. Immunohistochemical analysis of ANGPTL4 and HIF-1 $\alpha$ expression in the 170 advanced gastric cancer tissues. (A) Expression of ANGPTL4 in the normal mucosa. ANGPTL4 was expressed in the cytoplasm of the fundic gland. Positive staining for ANGPTL4 was observed in the cytoplasm of the gastric cancer cells. (B) Strongly positive and (C) weakly positive staining are shown in the magnified inset images (x400 magnification). Normal glands, which are strongly stained, can be observed in the top of image (C) (x100 magnification). (D) Negative staining of ANGPTL4. (E) Immunohistochemical staining of HIF-1 $\alpha$ in the nucleus and cytoplasm of the cancer cells (x100 magnification; inset, x400 magnification). (F) Negative staining of HIF-1 $\alpha$. HIF-1 $\alpha$, hypoxia inducible factor 1 $\alpha$; ANGPTL4, angiopoietin-like protein 4.
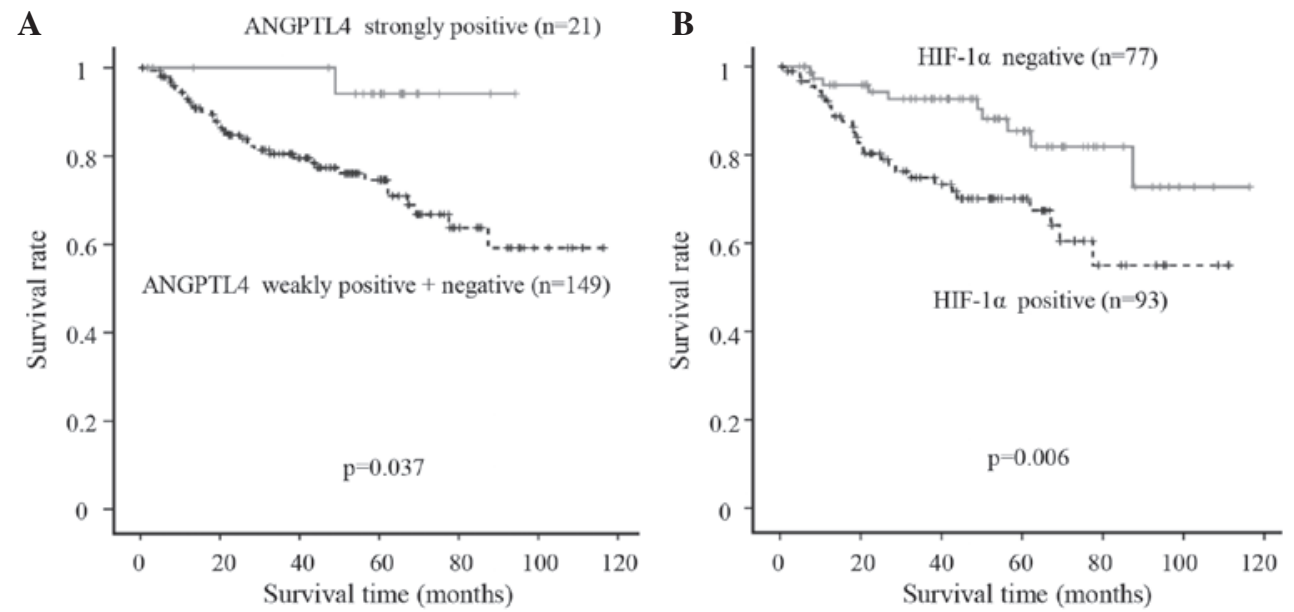

Figure 3. Kaplan-Meier curves of disease-free survival estimated according to the ANGPTL4 and HIF-1 $\alpha$ expression levels. (A) The strongly positive ANGPTL4 group showed a significantly longer disease-specific survival time than the other groups. (B) By contrast, the disease-specific survival time of the HIF-1 $\alpha$-positive patients was significantly shorter than that of the HIF-1 $\alpha$-negative patients. HIF-1 $\alpha$, hypoxia inducible factor $1 \alpha$; ANGPTL4, angiopoietin-like protein 4.

mRNA expression in the 58As9-SC cells was induced under hypoxia, with a fold induction of 63 times for $12 \mathrm{~h}, 26$ times for $24 \mathrm{~h}$ and 17 times for $48 \mathrm{~h}$. The hypoxic induction of ANGPTL4 mRNA in the 58As9-KD cells was decreased by only a small amount compared with that observed in the 58As9-SC cells, as the estimated fold induction remained at 47 times for $12 \mathrm{~h}, 22$ times for $24 \mathrm{~h}$ and 17 times for $48 \mathrm{~h}$.

Immunohistochemistry for ANGPTL4 and HIF-1 $\alpha$. The ANGPTL4 and HIF-1 $\alpha$ expression levels were evaluated using immunohistochemistry in 170 advanced gastric cancer tissues (Fig. 2). In the normal stomach tissues, ANGPTL4 expression was observed in the cytoplasm of the fundic gland cells (Fig. 2A). Strongly positive ANGPTL4 expression was observed in 21 out of 170 (12.4\%) gastric adenocarcinoma tissues, showing strong staining in the cytoplasm of the cancer cells (Fig. 2B). By contrast, weakly positive ANGPTL4 staining was observed in 60 out of 170 (35.3\%) samples (Fig. 2C), whereas negative staining was noted in 89 out of $170(52.3 \%)$ samples (Fig. 2D). In addition, the HIF-1 $\alpha$ expression was immunohistochemically evaluated in the 170 cancer specimens. Consequently, positive HIF-1 $\alpha$ expression with cytoplasmic and nuclear staining of the cancer cells was noted in 95 out of $170(55.9 \%)$ specimens (Fig. 2E), while negative staining was found in 75 out of $170(44.1 \%)$ specimens (Fig. 2F). 
Table II. Correlations between the ANGPTL4 and HIF-1 $\alpha$ expression levels and clinicopathological factors.

\begin{tabular}{|c|c|c|c|c|c|c|}
\hline \multirow[b]{2}{*}{ Factor } & \multicolumn{3}{|c|}{ ANGPTL4 } & \multicolumn{3}{|c|}{$\mathrm{HIF}-1 \alpha$} \\
\hline & $\begin{array}{l}\text { Strongly positive } \\
\qquad(\mathrm{n}=21)\end{array}$ & $\begin{array}{c}\text { Weakly positive } \\
\text { plus negative }(n=149)\end{array}$ & P-value ${ }^{a}$ & $\begin{array}{l}\text { Positive } \\
(n=95)\end{array}$ & $\begin{array}{l}\text { Negative } \\
(\mathrm{n}=75)\end{array}$ & P-value ${ }^{a}$ \\
\hline Age, years $($ mean $\pm S D)$ & $69.2 \pm 9.91$ & $68.4 \pm 11.4$ & 0.759 & $68.5 \pm 12.0$ & $68.6 \pm 10.2$ & 0.975 \\
\hline \multicolumn{7}{|l|}{ Gender, $\mathrm{n}$} \\
\hline Male & 13 & 100 & 0.629 & 64 & 49 & 0.870 \\
\hline Female & 8 & 49 & & 31 & 26 & \\
\hline \multicolumn{7}{|l|}{ Histology, n } \\
\hline Differentiated & 11 & 57 & 0.240 & 36 & 32 & 0.533 \\
\hline Undifferentiated & 10 & 92 & & 59 & 43 & \\
\hline \multicolumn{7}{|l|}{ Tumor depth, $\mathrm{n}$} \\
\hline 2 & 10 & 35 & 0.032 & 20 & 25 & 0.082 \\
\hline $3 / 4$ & 11 & 114 & & 75 & 50 & \\
\hline \multicolumn{7}{|l|}{ Lymph node metastasis, $\mathrm{n}$} \\
\hline- & 9 & 54 & 0.631 & 37 & 26 & 0.632 \\
\hline+ & 12 & 95 & & 58 & 49 & \\
\hline \multicolumn{7}{|l|}{ Lymphatic invasion, $\mathrm{n}$} \\
\hline- & 3 & 32 & 0.573 & 21 & 14 & 0.703 \\
\hline+ & 18 & 117 & & 74 & 61 & \\
\hline \multicolumn{7}{|l|}{ Vascular invasion, $\mathrm{n}$} \\
\hline- & 14 & 78 & 0.249 & 43 & 49 & 0.013 \\
\hline+ & 7 & 71 & & 52 & 26 & \\
\hline \multicolumn{7}{|l|}{ Stage, $\mathrm{n}$} \\
\hline $\mathrm{I} / \mathrm{II}$ & 15 & 74 & 0.067 & 47 & 42 & 0.441 \\
\hline III & 6 & 75 & & 48 & 33 & \\
\hline \multicolumn{7}{|l|}{ Adjuvant, $\mathrm{n}$} \\
\hline- & 14 & 88 & 0.636 & 56 & 46 & 0.875 \\
\hline+ & 7 & 61 & & 39 & 29 & \\
\hline \multicolumn{7}{|l|}{ ANGPTL4, n } \\
\hline Strongly positive & - & - & - & 8 & 13 & 0.101 \\
\hline $\begin{array}{l}\text { Weakly positive } \\
\text { plus negative }\end{array}$ & & & & 87 & 62 & \\
\hline
\end{tabular}

${ }^{\mathrm{a}} \chi^{2}$ test. HIF-1 $\alpha$, hypoxia inducible factor $1 \alpha$; ANGPTL4, angiopoietin-like protein 4.

Patient characteristics and clinicopathological features. The clinicopathological characteristics of the gastric cancer patients who underwent gastrectomy are summarized in Table I. The 170 patients consisted of 113 males and 57 females, ranging in age from 26 to 88 years (median, 71 years). The performed surgeries included distal gastrectomy in 71 patients $(41.8 \%)$, total gastrectomy in 98 patients $(57.6 \%)$ and proximal gastrectomy in 1 patient $(0.59 \%)$. The histological diagnosis of the resected cancer tissues was classified as a differentiated type of carcinoma in 68 cases $(40.0 \%)$ and an undifferentiated type in 102 cases $(60.0 \%)$. The tumor depth (T) was histologically determined as T2 in 46 cases $(27.1 \%), \mathrm{T} 3$ in 69 cases $(40.6 \%)$, T4a in 51 cases $(30.0 \%)$ and $\mathrm{T} 4 \mathrm{~b}$ in 4 cases $(2.4 \%)$, and the degree of lymph node metastasis was defined as N0 in 63 cases $(37.1 \%)$, $\mathrm{N} 1$ in 36 cases $(21.2 \%), \mathrm{N} 2$ in 26 cases $(15.3 \%), \mathrm{N} 3 \mathrm{a}$ in
16 cases $(9.4 \%)$ and $\mathrm{N} 3 \mathrm{~b}$ in 29 cases (17.1\%). Positive vascular invasion into the lymph and blood vessels was detected in 36 $(21.2 \%)$ and $90(52.9 \%)$ tissues, respectively. The tumor stage was determined to be IB in 28 cases (16.5\%), IIA in 36 cases (21.2\%), IIB in 26 cases (16.5\%), IIIA in 29 cases $(15.3 \%)$, IIIB in 26 cases $(15.3 \%)$ and IIIC in 25 cases $(14.7 \%)$.

Comparison between the clinicopathological factors and ANGPTL4 and HIF-1 $\alpha$ expression in the 170 gastric cancer patients. Table II shows the correlations between several clinicopathological factors and the ANGPTL4 and HIF-1 $\alpha$ expression levels. Strongly positive ANGPTL4 expression was found to be significantly correlated with the tumor depth (T) (Table II). In addition, cancer invasion was significantly deeper in the cases with weakly positive or negative ANGPTL4 expression $(n=149)$ compared with the strongly positive cases 
Table III. Univariate and multivariate analyses of the disease-specific survival of the 170 gastric cancer patients.

\begin{tabular}{|c|c|c|c|c|}
\hline \multirow[b]{3}{*}{ Factor } & \multicolumn{4}{|c|}{ Disease-specific survival } \\
\hline & \multicolumn{2}{|c|}{ Univariate analysis } & \multicolumn{2}{|c|}{ Multivariate analysis } \\
\hline & HR $(95 \% \mathrm{CI})$ & P-value & HR $(95 \% \mathrm{CI})$ & P-value \\
\hline \multicolumn{5}{|l|}{ Age, years } \\
\hline$<65$ & 1 & & & \\
\hline$\geq 65$ & $1.245(0.633-2.451)$ & 0.524 & & \\
\hline \multicolumn{5}{|l|}{ Gender } \\
\hline Male & 1 & & & \\
\hline Female & $0.972(0.500-1.891)$ & 0.934 & & \\
\hline \multicolumn{5}{|l|}{ Histology } \\
\hline Differentiated & 1 & & & \\
\hline Undifferentiated & $0.876(0.461-1.645)$ & 0.669 & & \\
\hline \multicolumn{5}{|l|}{ Tumor depth } \\
\hline 2 & 1 & & 1 & \\
\hline $3 / 4$ & $4.854(1.493-15.635)$ & 0.009 & $1.767(0.498-6.250)$ & 0.379 \\
\hline \multicolumn{5}{|l|}{ Lymph node metastasis } \\
\hline- & 1 & & 1 & \\
\hline+ & $14.493(3.497-58.824)$ & $<0.001$ & $10.204(1.927-52.632)$ & 0.006 \\
\hline \multicolumn{5}{|l|}{ Lymphatic invasion } \\
\hline- & 1 & & 1 & \\
\hline+ & $4.016(1.236-12.987)$ & 0.021 & $0.842(0.212-3.344)$ & 0.807 \\
\hline \multicolumn{5}{|l|}{ Vascular invasion } \\
\hline- & 1 & & 1 & \\
\hline+ & $2.392(1.245-4.587)$ & 0.009 & $1.727(0.847-3.521)$ & 0.132 \\
\hline \multicolumn{5}{|l|}{ Stage } \\
\hline $\mathrm{I} / \mathrm{II}$ & 1 & & 1 & \\
\hline III & $5.780(2.646-12.658)$ & $<0.001$ & $1.883(0.720-4.926)$ & 0.197 \\
\hline \multicolumn{5}{|l|}{ Adjuvant } \\
\hline- & 1 & & 1 & \\
\hline+ & $2.169(1.157-4.065)$ & 0.016 & $0.771(0.390-1.524)$ & 0.455 \\
\hline \multicolumn{5}{|l|}{ ANGPTL4 } \\
\hline Weakly positive plus negative & 1 & & & \\
\hline Strongly positive & $0.142(0.019-1.034)$ & 0.054 & & \\
\hline \multicolumn{5}{|l|}{ HIF- $1 \alpha$} \\
\hline Negative & 1 & & 1 & \\
\hline Positive & $2.375(1.186-4.762)$ & 0.015 & $2.336(1.119-4.878)$ & 0.024 \\
\hline
\end{tabular}

HIF-1 $\alpha$, hypoxia inducible factor $1 \alpha$; ANGPTL4, angiopoietin-like protein 4; HR, hazard ratio; CI, confidence interval.

$(\mathrm{n}=21)(\mathrm{P}=0.032)$. Meanwhile, the tumor stage tended to be lower in the strongly positive ANGPTL4cases compared with the other cases; however, the difference was not statistically significant $(\mathrm{P}=0.067)$. A comparative analysis of the patients with strongly or weakly positive ANGPTL4 expression and those with negative expression did not reveal any significant differences among the clinicopathological factors (data not shown). On the other hand, the patients with positive HIF-1 $\alpha$ expression presented with a significantly higher degree of vascular invasion compared with those with negative expression $(\mathrm{P}=0.013)$ (Table II). There were no significant correlations between strongly positive ANGPTL4 expression and HIF-1 $\alpha$ expression (Table II).

ANGPTL4 and HIF-1 $\alpha$ expression levels and patient outcomes. The associations between the patient outcomes and the levels of ANGPTL4 and HIF-1 $\alpha$ expression were statistically analyzed in 170 patients with advanced gastric cancer (Fig. 3). The disease-specific survival of the patients with strongly positive ANGPTL4 expression $(n=21)$ was significantly more favorable than that of the other patients $(n=149)$ $(\mathrm{P}=0.037)$. By contrast, the disease-specific survival rate of the 
HIF-1 $\alpha$-positive patients $(n=93)$ was significantly worse than that of the HIF-1 $\alpha$-negative patients $(n=77)(P=0.006)$.

Univariate and multivariate analyses of disease-specific survival. A univariate analysis of the 170 patients revealed that the tumor depth, lymph node metastasis, lymphatic invasion, vascular invasion, tumor stage, adjuvant chemotherapy and HIF-1 $\alpha$ expression were significantly associated with the disease-specific survival (Table III). A multivariate analysis using these factors was carried out according to Cox's proportional hazards model. Consequently, the multivariate analysis confirmed that lymph node invasion and HIF-1 $\alpha$ expression were independent predictive factors for disease-specific survival ( $\mathrm{P}=0.006$ and $\mathrm{P}=0.024$, respectively) (Table III).

\section{Discussion}

The present study first investigated the expression levels of ANGPTL4 mRNA in 10 gastric cancer cell lines under normoxic and hypoxic conditions. Notably, ANGPTL4 expression was significantly induced under hypoxia in 7 of the cell lines (MKN1, MKN7, 44As3, 58As9, HSC45, HSC57 and KATOIII), whereas no such expression was found in the remaining 3 cell lines (MKN8, MKN45 and MKN74), under normoxia and hypoxia. In order to investigate whether hypoxia-induced ANGPTL4 expression is HIF-1 $\alpha$ dependent in gastric cancer cells, ANGPTL4 expression was compared between the HIF-1 $\alpha$-knockdown 58As9-KD cells and the control 58As9-SC cells established from ANGLTL4-expressing 58As9 parent cells (11). The results of the analysis showed that the hypoxic induction of ANGPTL4 was weakened with a small amount of 58As9-KD cells compared with that observed in the 58As9-SC cells. By contrast, the hypoxia-induced expression of CA9, which is known to be directly regulated by HIF-1 $\alpha$, was markedly diminished in the 58As9-KD cells compared with that observed in the 58As9-SC cells. These results indicate that hypoxia-induced ANGPTL4 expression may be preserved without HIF-1 $\alpha$ in hypoxic 58As9 gastric cancer cells. It is possible that HIF-1 $\alpha$, as well as other HIF-a family members, such as HIF- $2 \alpha$ and HIF-3 $\alpha$, or other factors regulate the hypoxia-induced ANGPTL4 expression in 58As9 cells (7). Although HIF-1 $\alpha$ dependency was not determined in the 6 other cell lines expressing ANGPTL4, the present results suggest that ANGPTL4 is induced under hypoxia predominantly via an HIF-1 $\alpha$-independent pathway in gastric cancer cells. In the immunohistochemical analysis, tumors with strongly positive ANGPTL4 expression exhibited significantly less tumor invasion. By contrast, those with positive HIF-1 $\alpha$ expression demonstrated significantly greater venous invasion. These results reflect the inverse effect of ANGPTL4 and HIF-1 $\alpha$ expression on cancer invasiveness. Furthermore, the survival time of the patients with strongly positive ANGPTL4 expression was significantly longer than that associated with the other expression patterns. Conversely, the survival time of the HIF-1 $\alpha$-positive patients was significantly shorter than that of the HIF-1 $\alpha$-negative patients. Moreover, the multivariate analysis revealed HIF-1 $\alpha$ to be an independent prognostic factor. Taken together, these results suggest that the hypoxic induction of ANGPTL4 is independently regulated by HIF-1 $\alpha$ and that ANGPTL4 expression may inhibit cancer invasion into the gastric wall, thus resulting in a longer survival time among patients with strongly positive ANGPTL4 expression.

To date, several studies have addressed the emerging roles of ANGPTL4 under conditions of tumor hypoxia. For example, Kim et al reported that ANGPTL4 induction by prostaglandin E2 under hypoxia promotes colorectal cancer growth (27), and Zhang et al demonstrated that the inhibition of HIF-1 $\alpha$ expression in breast cancer cells by RNA interference disturbs primary tumor growth and metastasis in severe combined immunodeficiency mice by blocking ANGPTL4 expression (28). Meanwhile, Li et al reported that HIF-1 $\alpha$-activated ANGPTL4 expression contributes to tumor metastasis via vascular cell adhesion molecule-1/integrin $\beta 1$ signaling in the setting of HCC (24). These studies demonstrate that HIF-1 $\alpha$-induced ANGPTL4 expression increases cancer cell aggressiveness under hypoxic conditions. By contrast, various studies have also shown that increased ANGPTL4 expression inhibits melanoma, lung and colorectal tumor growth, as well as metastasis and angiogenesis (37,38). High ANGPTL4 expression in mouse tumors also impairs tumor cell migration and invasiveness, thereby inhibiting metastasis (37). These studies demonstrate the inhibitory roles of ANGPTL4 in cancer progression and support the findings of the present study. Although the reasons for the aforementioned discrepancies are unclear, it can be speculated that the flANGPTL4, nANGPTL4 and cANGPTL4 domains, which have distinct biological functions, are differentially expressed in various cancers.

In conclusion, the present study demonstrated for the first time that ANGPTL4 expression is predominantly regulated via an HIF-1 $\alpha$-independent pathway under hypoxia in gastric cancer cells. High ANGPTL4 expression may inhibit tumor invasion and potentially serves as a favorable marker for predicting a long survival time in advanced gastric cancer patients. Gastric cancer tissues, which are exposed to a hypoxic environment, and HIF-1 $\alpha$ expression may increase malignant behavior by upregulating target genes. By contrast, a hypoxic environment may induce ANGPTL4 expression via an HIF-1 $\alpha$-independent pathway and thus suppress tumor invasion. Recombinant ANGPTL4 may therefore be useful as a novel pharmacological agent for inhibiting the invasion of gastric cancer cells.

\section{References}

1. Guggenheim DE and Shah MA: Gastric cancer epidemiology and risk factors. J Surg Oncol 107: 230-236, 2013.

2. Kamangar F, Dores GM and Anderson WF: Patterns of cancer incidence, mortality and prevalence across five continents: Defining priorities to reduce cancer disparities in different geographic regions of the world. J Clin Oncol 24: 2137-2150, 2006.

3. Höckel M and Vaupel P: Tumor hypoxia: Definitions and current clinical, biologic and molecular aspects. J Natl Cancer Inst 93: 266-276, 2001

4. Kitajima Y and Miyazaki K: The Critical Impact of HIF-1 $\alpha$ on Gastric Cancer Biology. Cancers (Basel) 5: 15-26, 2013.

5. Semenza GL: Hypoxia-inducible factors: Mediators of cancer progression and targets for cancer therapy. Trends Pharmacol Sci 33: 207-214, 2012.

6. Semenza GL: Hypoxia-inducible factor 1: Regulator of mitochondrial metabolism and mediator of ischemic preconditioning. Biochim Biophys Acta 1813: 1263-2168, 2011.

7. Keith B, Johnson RS and Simon MC: HIF1 $\alpha$ and HIF2 $\alpha$ : Sibling rivalry in hypoxic tumour growth and progression. Nat Rev Cancer 12: 9-22, 2011. 
8. Rey S and Semenza GL: Hypoxia-inducible factor-1-dependent mechanisms of vascularization and vascular remodelling. Cardiovasc Res 86: 236-242, 2010.

9. Koh MY, Lemos R Jr, Liu X and Powis G: The hypoxia-associated factor switches cells from HIF-1 $\alpha$ - to HIF- $2 \alpha$-dependent signaling promoting stem cell characteristics, aggressive tumor growth and invasion. Cancer Res 71: 4015-4027, 2011.

10. Nakamura J, Kitajima Y, Kai K, Hashiguchi K, Hiraki M, Noshiro $\mathrm{H}$ and Miyazaki K: HIF-1alpha is an unfavorable determinant of relapse in gastric cancer patients who underwent curative surgery followed by adjuvant 5-FU chemotherapy. Int J Cancer 127 : 1158-1171, 2010.

11. Miyake S, Kitajima Y, Nakamura J, Kai K, Yanagihara K, Tanaka T, Hiraki M, Miyazaki K and Noshiro H: HIF-1 $\alpha$ is a crucial factor in the development of peritoneal dissemination via natural metastatic routes in scirrhous gastric cancer. Int J Oncol 43: 1431-1440, 2013.

12. Yoshimura H, Dhar DK, Kohno H, Kubota H, Fujii T, Ueda S, Kinugasa S, Tachibana M and Nagasue N: Prognostic impact of hypoxia-inducible factors 1alpha and 2alpha in colorectal cancer patients: Correlation with tumor angiogenesis and cyclooxygenase-2 expression. Clin Cancer Res 10: 8554-8560, 2004.

13. Kim I, Kim HG, Kim H, Kim HH, Park SK, Uhm CS, Lee ZH and Koh GY: Hepatic expression, synthesis and secretion of a novel fibrinogen/angiopoietin-related protein that prevents endothelial-cell apoptosis. Biochem J 346: 603-610, 2000.

14. Mandard S, Zandbergen F, Tan NS, Escher P, Patsouris D, Koenig W, Kleemann R, Bakker A, Veenman F, Wahli W, et al: The direct peroxisome proliferator-activated receptor target fasting-induced adipose factor (FIAF/PGAR/ANGPTL4) is present in blood plasma as a truncated protein that is increased by fenofibrate treatment. J Biol Chem 279: 34411-34420, 2004.

15. Yoon JC, Chickering TW, Rosen ED, Dussault B, Qin Y, Soukas A, Friedman JM, Holmes WE and Spiegelman BM: Peroxisome proliferator-activated receptor gamma target gene encoding a novel angiopoietin-related protein associated with adipose differentiation. Mol Cell Biol 20: 5343-5349, 2000.

16. Yoshida K, Shimizugawa $\mathrm{T}$, Ono $\mathrm{M}$ and Furukawa $\mathrm{H}$ Angiopoietin-like protein 4 is a potent hyperlipidemia-inducing factor in mice and inhibitor of lipoprotein lipase. J Lipid Res 43: $1770-1772,2002$

17. Tan MJ, Teo Z, Sng MK, Zhu P and Tan NS: Emerging roles of angiopoietin-like 4 in human cancer. Mol Cancer Res 10: 677-688, 2012.

18. Lei X, Shi F, Basu D, Huq A, Routhier S, Day R and Jin W: Proteolytic processing of angiopoietin-like protein 4 by proprotein convertases modulates its inhibitory effects on lipoprotein lipase activity. J Biol Chem 286: 15747-15756, 2011.

19. Ge H, Yang G, Huang L, Motola DL, Pourbahrami T and Li C: Oligomerization and regulated proteolytic processing of angiopoietin-like protein 4. J Biol Chem 279: 2038-2045, 2004

20. Oike Y, Akao M, Kubota Y and Suda T: Angiopoietin-like proteins: Potential new targets for metabolic syndrome therapy. Trends Mol Med 11: 473-479, 2005.

21. Katoh Y and Katoh M: Comparative integromics on Angiopoietin family members. Int J Mol Med 17: 1145-1149, 2006.

22. Hato T, Tabata M and Oike Y: The role of angiopoietin-like proteins in angiogenesis and metabolism. Trends Cardiovasc Med 18: 6-14, 2008 .

23. Zhu P, Goh YY, Chin HF, Kersten Sand Tan NS: Angiopoietin-like 4: A decade of research. Biosci Rep 32: 211-219, 2012.

24. Li H, Ge C, Zhao F, Yan M, Hu C, Jia D, Tian H, Zhu M, Chen T, Jiang G, et al: Hypoxia-inducible factor 1 alpha-activated angiopoietin-like protein 4 contributes to tumor metastasis via vascular cell adhesion molecule-1/integrin $\beta 1$ signaling in human hepatocellular carcinoma. Hepatology 54: 910-919, 2011.
25. Nakayama T, Hirakawa H, Shibata K, Nazneen A, Abe K, Nagayasu T and Taguchi T: Expression of angiopoietin-like 4 (ANGPTL4) in human colorectal cancer: ANGPTL4 promotes venous invasion and distant metastasis. Oncol Rep 25: 929-935, 2011.

26. Akishima-Fukasawa Y, Ishikawa Y, Akasaka Y, Uzuki M, Inomata $\mathrm{N}$, Yokoo $\mathrm{T}$, Ishii R, Shimokawa R, Mukai K, Kiguchi $\mathrm{H}$, et al: Histopathological predictors of regional lymph node metastasis at the invasive front in early colorectal cancer. Histopathology 59: 470-481, 2011

27. Kim SH, Park YY, Kim SW, Lee JS, Wang D and DuBois RN: ANGPTL4 induction by prostaglandin E2 under hypoxic conditions promotes colorectal cancer progression. Cancer Res 71: 7010-7020, 2011.

28. Zhang H, Wong CC, Wei H, Gilkes DM, Korangath $\mathrm{P}$ Chaturvedi P, Schito L, Chen J, Krishnamachary B, Winnard PT Jr, et al: HIF-1-dependent expression of angiopoietin-like 4 and L1CAM mediates vascular metastasis of hypoxic breast cancer cells to the lungs. Oncogene 31: 1757-1770, 2012

29. Padua D, Zhang XH, Wang Q, Nadal C, Gerald WL, Gomis RR and Massagué J: TGFbeta primes breast tumors for lung metastasis seeding through angiopoietin-like 4. Cell 133: 66-77, 2008

30. Ifon ET, Pang AL, Johnson W, Cashman K, Zimmerman S, Muralidhar S, Chan WY, Casey J and Rosenthal LJ: U94 alters FN1 and ANGPTL4 gene expression and inhibits tumorigenesis of prostate cancer cell line PC3. Cancer Cell Int 5: 19, 2005.

31. Le Jan S, Amy C, Cazes A, Lamandé N, Favier J, Philippe J, Sibony M, Gasc JM, Corvol P and Germain S: Angiopoietin-like 4 is a proangiogenic factor produced during ischemia and in conventional renal cell carcinoma. Am J Pathol 162: 1521-1528, 2003.

32. Verine J, Lehmann-Che J, Soliman H, Feugeas JP, Vidal JS, Mongiat-Artus P, Belhadj S, Philippe J, Lesage M, Wittmer E, et al: Determination of angpt14 mRNA as a diagnostic marker of primary and metastatic clear cell renal-cell carcinoma. PLoS One 5: e10421, 2010.

33. Hu J, Jham BC, Ma T, Friedman ER, Ferreira L, Wright JM, Accurso B, Allen CM, Basile JR and Montaner S: Angiopoietin-like 4: A novel molecular hallmark in oral Kaposi's sarcoma. Oral Oncol 47: 371-375, 2011.

34. Ma T, Jham BC, Hu J, Friedman ER, Basile JR, Molinolo A, Sodhi A and Montaner S: Viral G protein-coupled receptor up-regulates Angiopoietin-like 4 promoting angiogenesis and vascular permeability in Kaposi's sarcoma. Proc Natl Acad Sci USA 107: 14363-14368, 2010.

35. Nakayama T, Hirakawa H, Shibata K, Abe K, Nagayasu T and Taguchi T: Expression of angiopoietin-like 4 in human gastric cancer: ANGPTL4 promotes venous invasion. Oncol Rep 24: 599-606, 2010

36. Japanese Gastric Cancer Association. Japanese classification of gastric carcinoma: 3rd English edition. Gastric Cancer 14: 101-112, 2011.

37. Galaup A, Cazes A, Le Jan S, Philippe J, Connault E, Le Coz E, Mekid H, Mir LM, Opolon P, Corvol P, et al: Angiopoietin-like 4 prevents metastasis through inhibition of vascular permeability and tumor cell motility and invasiveness. Proc Natl Acad Sci USA 103: 18721-18726, 2006

38. Ito Y, Oike Y, Yasunaga K, Hamada K, Miyata K, Matsumoto S, Sugano S, Tanihara H, Masuho Y and Suda T: Inhibition of angiogenesis and vascular leakiness by angiopoietin-related protein 4. Cancer Res 63: 6651-6657, 2003. 